\title{
Detection of Abnormal Cervical Cytology in Papanicolaou Smears in a Tertiary Care Center
}

\author{
Suspana Hirachand, ${ }^{1}$ Junu Bajracharya, ${ }^{2}$ Sabi Pradhanang, ${ }^{1}$ Sanju Lama' \\ 'Department of Pathology, KMCTH, Kathmandu, Nepal, ${ }^{2}$ Department of Obstretics and Gynaecology, KMCTH, Kathmandu, \\ Nepal
}

\section{ABSTRACT}

Introduction: Cancer of uterine cervix is a leading cause of mortality and morbidity among women worldwide. In developing countries it is the most common gynaecological cancer and one of the leading causes of cancer death among women. Pap smears are commonly used as cytological screening test for successful eradication of precancerous lesions, which has made it a routine procedure worldwide.

Methods: This descriptive study was conducted at Kathmandu Medical College Teaching Hospital, Kathmandu within a period of two years from January 2011 to December 2012. A total of 1369 cases were screened.

Results: In this study, cytological examination of the smears showed 944 (68.95\%) inflammatory smears, 301(21.99\%) normal smears, 101(7.38\%) atrophic smears, seven (0.51\%) ASCUS, two (0.15\%) LSIL, four $(0.29 \%)$ HSIL and two $(0.15 \%)$ squamous cell carcinoma. Radiation changes were seen in three $(0.22 \%)$ cases. Of all the smears studied five $(0.36 \%)$ cases were inadequate. Regarding ethnicity, incidence of epithelial cell abnormalities was high in Tamang (5 cases). Eleven cases (73.33\%) of epithelial cell abnormalities were seen in patients from urban areas.

Conclusions: In country like Nepal with predominant rural population, screening and awareness programs with co-operation of media, non-government organizations and government should be formulated for early detection of cervical cancer.

Keywords: Bethesda system; cervical intraepithelial lesions; pap smear.

\section{INTRODUCTION}

Cancer of uterine cervix is a leading cause of mortality and morbidity among women worldwide. In developing countries it is the most common gynaecological cancer and one of the leading causes of cancer death among women. Approximately 2 million women are suffering from cervical cancer worldwide, with 500,000 new cases and 280,000 cervical cancer related deaths annually. ${ }^{1-5}$ Particularly in developing countries, the high incidence of cervical cancer is an important health issue. Regarding the prevalence of cervical cancer, studies in different countries have reported varying results. For example, the risk of a women developing cervical cancer during her lifetime is $1 / 116$ in England versus $1 / 26$ in South Africa. ${ }^{6-10}$ In developing countries the higher prevalence of cervical cancer is seen mainly due to the suboptimal or ineffective screening programmes. Barries to cervical cancer screening uptake include geographic and economic inaccessibility of services, poor quality of services, lack of support from families and communities, absence of knowledge

Correspondence: Dr. Suspana Hirachand, Department of Pathology, KMCTH, Kathmandu, Nepal, E-mail: suspi1974@hotmail.com. 
about the disease and lack of familiarity with the concept of preventive health care. ${ }^{11}$ Unlike most other malignancies, cancer of cervix is readily preventable as it is easy to detect and treat its precursor lesion. ${ }^{12}$ Papanicolaou cytological smear, since its introduction there has been a dramatic reduction in the incidence and mortality of invasive cervical cancer worldwide. ${ }^{13}$

Pap smear is a simple, convenient, inexpensive, reliable and repeatable test for early screening of the cervical lesion and most widely used system for describing Pap smear result is The 2001 Bethesda system (TBS). The present study was conducted to determine the prevalence of cervical intraepithelial lesions.

\section{METHODS}

This descriptive study was conducted at Kathmandu Medical College Teaching Hospital, Kathmandu within a period of two years from January 2011 to December 2012. A total of 1369 cases were screened. All cases were included in the study. Cervical smears were collected by gynaecologist with Ayers wooden spatula which was rotated $360^{\circ}$ over cervix, sampling both ecto and endocervix. Slides were prepared, labeled, fixed in $95 \%$ ethyl alcohol immediately and subsequently stained with Papanicolaou stain. After staining slides were mounted with DPX (Distrene dibutyl phthalate xylene), screened and reported according to the 2001 Bethesda system. Statistical analysis was done using Microsoft excel and SPSS 16.0.

\section{RESULTS}

Total 1369 cervical smears were studied. Patient age ranged from $20-78$ years. The most common symptom in present study was vaginal discharge followed by lower abdominal pain (Table 1).

\begin{tabular}{|ll|}
\hline $\begin{array}{l}\text { Table 1. Distribution of patients according to } \\
\text { symptoms. }\end{array}$ \\
\hline Symptoms & $\begin{array}{l}\text { No. of patients } \\
(\mathbf{n}=1369)(\%)\end{array}$ \\
Vaginal discharge & $624(45.58)$ \\
Lower abdominal pain & $302(22.06)$ \\
Backache & $110(8.03)$ \\
Post coital bleeding & $26(1.90)$ \\
Post menopausal bleeding & $12(0.88)$ \\
Routine screening & $295(21.55)$ \\
Total & 1369 \\
\hline
\end{tabular}

The cytological examination of the smears showed 944 (68.95\%) inflammatory smears (Table 2), 301 (21.99\%) normal smears, 101 (7.38\%) atrophic smears, seven $(0.51 \%$ ) ASCUS (Atypical cells of undetermined significance), two $(0.15 \%)$ LSIL(Low grade squamous intraepithelial lesion), four (0.29\%) HSIL (High grade squamous intraepithelial lesion) and two (0.15\%) SCC(squamous cell carcinoma). Radiation changes were seen in three $(0.22 \%)$ cases. Of all the smears studied five $(0.36 \%)$ cases were inadequate. Inflammatory smears were more common in $20-40$ years age group where as epithelial cell abnormalities were common between 41-50 years (Table 3 ). Regarding ethnicity, incidence of epithelial cell abnormalities was high in Tamang (5 cases) (Table 4 ). Eleven cases $(73.33 \%$ ) of epithelial cell abnormalities were seen in patients from urban areas (Table 5).

\begin{tabular}{|lllclll|}
\hline \multicolumn{7}{|l|}{ Table 2. Relation of age with various lesions on cervical Pap smear. } \\
\hline Cytological diagnosis & $\mathbf{2 0 - 3 0}$ years & $\mathbf{3 1 - 4 0}$ years & $\mathbf{4 1 - 5 0}$ years & $\mathbf{5 1 - 6 0}$ years & $\mathbf{7} \mathbf{6 1}$ years & Total (\%) \\
Inflammatory smear & 374 & 301 & 215 & 34 & 20 & 944 (68.95) \\
Normal smear & 156 & 64 & 50 & 16 & 15 & $301(21.99)$ \\
Atrophic smear & 0 & 0 & 10 & 47 & 44 & $101(7.38)$ \\
Inadequate & 1 & 3 & 1 & 0 & 0 & $5(0.36)$ \\
ASCUS & 0 & 2 & 4 & 1 & 0 & $7(0.51)$ \\
LSIL & 0 & 2 & 0 & 0 & 0 & $2(0.15)$ \\
HSIL & 0 & 1 & 3 & 0 & 0 & $4(0.29)$ \\
SCC & 0 & 0 & 2 & 0 & 0 & $2(0.15)$ \\
Radiation changes & 0 & 0 & 2 & 1 & 0 & $3(0.22)$ \\
Total & 531 & 373 & 283 & 99 & 79 & $1369(100)$ \\
\hline
\end{tabular}


Table 3. Inflammatory lesions on Pap smear.

\begin{tabular}{|ll|}
\hline Inflammatory lesions & $\begin{array}{l}\text { No. of patients } \\
(\mathbf{n}=944) \text { (Percentage) }\end{array}$ \\
Inflammation & $911(96.50)$ \\
Trichomonas vaginalis & $26(2.75)$ \\
Candida & $05(0.54)$ \\
Herpis simplex virus & $02(0.21)$ \\
\hline
\end{tabular}

Table 4. Distribution of epithelial cell abnormalities according to ethnicity.

\begin{tabular}{|lllllll|}
\hline Ethnicity & $\begin{array}{l}\text { Total } \\
\text { no.of } \\
\text { patients }\end{array}$ & ASCUS & LSIL & HSIL & SCC & Total $(\%)$ \\
Brahman & 523 & 2 & 0 & 0 & 0 & $2(0.38)$ \\
Chhetri & 389 & 3 & 0 & 0 & 0 & $3(0.78)$ \\
Newar & 186 & 1 & 1 & 0 & 0 & $2(1.07)$ \\
Tamang & 115 & 1 & 1 & 2 & 1 & $5(4.35)$ \\
Gurung & 97 & 0 & 0 & 1 & 0 & $1(1.03)$ \\
Magar & 34 & 0 & 0 & 1 & 0 & $1(2.94)$ \\
Tharu & 25 & 0 & 0 & 0 & 1 & $1(4)$ \\
Total & 1369 & 7 & 2 & 4 & 2 & 15 \\
\hline
\end{tabular}

Table 5. Distribution of epithelial cell abnormalities according to locality.

\begin{tabular}{|llllll|}
\hline Locality & ASCUS & LSIL & HSIL & SCC & Total (\%) \\
Urban & 5 & 2 & 3 & 1 & $11(73.33)$ \\
Rural & 2 & 0 & 1 & 1 & $4(26.67)$ \\
Total & 7 & 2 & 4 & 2 & 15 \\
\hline
\end{tabular}

\section{DISCUSSION}

In developing countries cancer has been a major cause of morbidity and mortality. It is due to the change in the life styles and demographic profiles, non-communicable diseases merging as an important health problem which demand appropriate control program before they assume epidemic propagation. ${ }^{14}$ According to American College of Obstetricians and Gynecologists (ACOG) and others recommend starting screening at 21 years. ${ }^{15,16}$ The incidence of cervical cancer has decreased more than $50 \%$ in the past 30 years because of widespread screening with cervical cytology. Considering the efficacy of Pap smear cytology in preventing cervical cancer, it is advocated that it should be initiated in all women at the age of 21 years. ${ }^{17,18}$ Out of all the exfoliative cytology, Pap smear has been regarded as the gold standard for cervical screening programs. ${ }^{19}$ The predominant population in the present study was between $20-40$ years $(66.55 \%)$ with the chief complaint of vaginal discharge in 624 cases $(45.58 \%)$, as in studies done by Sharwani RK et al and Tirumalasatti $\mathrm{N}$ et al. ${ }^{20,21}$ The common cytological diagnosis was inflammatory smear, predominant population being $20-40$ years, as it is the reproductive age and the majority of infections are sexually transmitted. In this study, there were 15 cases $(1.09 \%)$ of epithelial cell abnormalities (Figure 1 ).

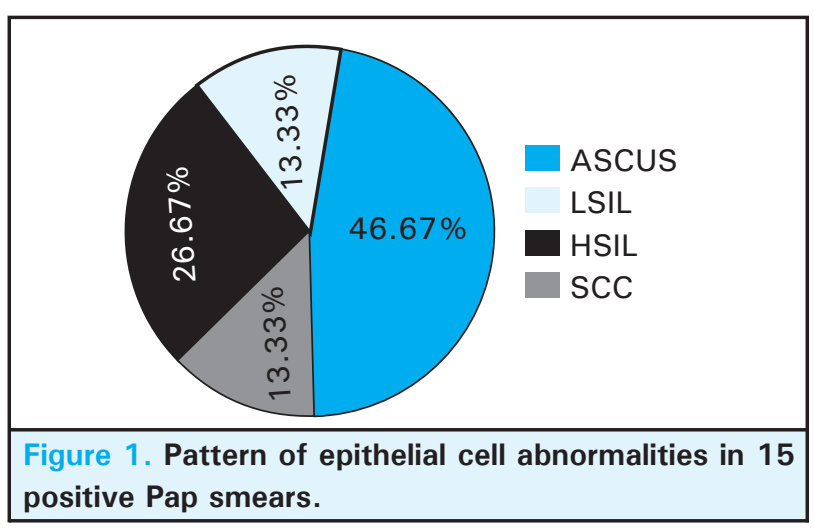

ASCUS was found to be highest (seven cases) in age group 31-50 years. The diagnosis of ASCUS is important as it progresses to LSIL, HSIL and squamous cell carcinoma. ${ }^{21,22}$ This study shows $60 \%$ of all abnormal epithelial lesions in women above 40 years of age. The incidence of high grade epithelial lesion increases with advancing age. In a study by Ranabhat SK et al, $80 \%$ of all abnormal epithelial lesions were found in the age group above 40 years. ${ }^{22}$ Another study by Mishra et al has found that $51.5 \%$ of squamous intraepithelial lesion cases and $75.3 \%$ of carcinoma cases were detected in women above 40 years of age. ${ }^{23}$

Although in many studies abnormal epithelial lesions were found in the age group above 40 years, the screening programme should start at 21 years of age. So if you catch them at early age than you can prevent further development of cancer. Screening guideline varies from country to country. In general, screening starts about the age of 20 or 25 and continues until about the age of 50 or 60 . Screening is typically recommended every 3 to 5 years as long as results are normal. ${ }^{24,25}$ Three yearly screening upto 39 years of age, prevents $41 \%$ of cancers. Five yearly screening between 40 and 60 years of age prevents $63 \%$ of cancers. ${ }^{26,27}$

Incidence of epithelial cell abnormalities was high in Tamang $(4.35 \%)$, because this ethnic population has low socio-economic status, women are married at early age, early child birth and multiparity, which are the frequent risk factors for cervical cancer. Though cervical cancer is said to be more common in rural population, in this study majority of epithelial cell abnormalities (73.33\%) were seen in population living in urban areas. It may be due to increase awareness, regular screening and easy accessibility of health care services.

So, health awareness programs by media, nongovernment organizations and government with their 
implementation in the form of screening camps would be a great help to women particularly in rural areas to detect cervical lesions.

\section{CONCLUSIONS}

Pap smear examination is widely accepted screening method. In country like Nepal with predominant rural population, screening and awareness programs with cooperation of media, non-government organizations and government should be formulated for early detection of cervical cancer.

\section{REFERENCES}

1. Cervical Cancer: ESMO Clinical Practice Guidelines for diagnosis, treatment and follow-up. European Society for Medical Oncology. 2010.

2. Abdullah LS. Pattern of abnormal Pap smears in developing countries: A report from a large referral hospital in Saudi Arabia using the revised 2001 Bethesda System. Ann Saudi Med. 2007;4(27):268-72.

3. Morris M, Tortolero-Luna G. Cervical intraepithelial neoplasia and cervical carcinoma. Obstet Gynecol Clin North Am. 1996; 23: 347-401.

4. Coleman M, Esteve J, Damieck P. Trends in cancer incidence and mortality. Cervix uteri. Lyon France: IARC Scientific Publication (No. 121); 1993:433.

5. The World Health Report 1995. Bridging the gaps. Geneva: World Health Organization. 1995.

6. Sahin S, Ozdemir K, Unsal A, Dogu O. The frequency of having pap smear tests among women between 15-64 years old and the evaluation of the level of their knowledge. J Pak Med Assoc. 2013; 63:873-7.

7. Jemel A, Siegel R, Ward E, Hao Y, Xu J, Murray T, et al. Cancer Statistic 2008. CA Cancer J Clin. 2008;58:71-96.

8. Sitas F, Madhoo J, Wessie J. National Cancer Registry of South Africa. Incidence of histologically diagnosed cancer in South Africa, 1993-1995. Johannesburg: South Africa Institute for Medical Research. 1998.

9. Wilson CM, Tobin S, Young C. The exploding worldwide cancer burden: The impact of cancer on women. Int J Gynecol Cancer. 2004;14:1-4.

10. Castellsague X. Natural history and epidemiology of HPV infection and cervical cancer. Gynecol Oncol. 2008;110:54-7.

11. Blank RG, Moss SM, Coleman DA, Swerdlow AJ. An examination of the role of opportunistic smear taking in NHS cervical screening programme using data from the CSEU cervical screening cohort study. BJOG. 2007;114:1408-13.

12. Bal MS, Goyal R, Suri AK, Mohi MK. Detection of abnormal cervical cytology in Papanicolaou smears. J Cytol. 2012;29:45-7.

13. Afrakhteh M, Khodakarami N, Moradi A, Alavi E, Shirazi FH. A study of 13315 papanicolaou smears diagnosis in Sohada hospital. J Fam Reprod Health. 2007; 1:79-9.
14. Patel MM, Pandey AN, Modi J. Cervical Pap smear study and its utility in cancer screening, to specify the strategy for cervical cancer control. National Journal of Community Medicine. 2011;2(1):49-51.

15. Cervical Cancer Screening. The American College of Obstetricians and Gynecologists. 2013.

16. Screening for Cervical Cancer. Current Recommendation. U.S. Preventive Service Task Force. 2012.

17. Andrae B, Andresson TM, Lambert PC. Screening and cervical cancer cure: Population based cohort study. BMJ. 2012 Mar 1;344.

18. ACOG Practice Bulletin. Clinical management guidelines for obstetrician-gynecologists. 2009.

19. Cheryl LR, Clair WM, Kevin R. Prevention of cervical cancer. Critical review in Oncology/Hematology. 2000;33:169-85.

20. Sharwani Rk, Khan T, Akhtar K, Zeba A, Siddiqui FA, Rehman K. Conventional Pap smear and liquid based cytology for cervical cancer screening. A comparative study. Journal of Cytology. 2007;24(4):167-72.

21. Tirumalasetti N, Navyaa VR. Utility of Pap smear study in the diagnosis of various neoplastic and non-neoplastic lesions of cervix. IJPRBS. 2012;1(5):379-89.

22. Ranabhat SK, Shrestha R, Tiwari M. Analysis of abnormal epithelial lesions in cervical Pap smears in Mid-western Nepal. Journal of Pathology of Nepal. 2011; 1:30-3.

23. Mishra S, Srivastava S, Singh U, Srivastava AN. Risk factors and strategies for control of carcinoma cervix in India. Hospital based cytological screening experience of 35 years. Indian J Cancer. 2009;46:155-9.

24. Strander B. At what age should cervical screening stop? Brit Med J. 2009;338: 1022-23

25. Arbyn M. European Guidelinesfor quality assurance in cervical cancer screening. Annals of Oncology. 2010;21(3):448-58

26. NHS Cervical screening Website.

27. Knot L. Cervical Screening (Cervical screen test). Cervical Lancet Oncol. 2012;13(13):78-88. 